\title{
Successful treatment with hyperbaric oxygen therapy for pneumatosis cystoides intestinalis as a complication of granulomatosis with polyangiitis: a case report
}

\author{
Kensuke Nakatani ${ }^{1}$, Takaharu Kato ${ }^{1,2^{*}}$, Shinichiro Okada ${ }^{1}$, Risa Matsumoto ${ }^{1}$, Kazuhiro Nishida ${ }^{1}$, \\ Hiroyasu Komuro' and Toshiyuki Suganuma'
}

\begin{abstract}
Background: Although gastrointestinal involvement in patients with granulomatosis with polyangiitis is uncommon, it is associated with mild to severe life-threatening complications. We present a case of pneumatosis cystoides intestinalis in a patient with granulomatosis with polyangiitis that was treated successfully with hyperbaric oxygen.

Case presentation: A 70-year-old Japanese man with a 3-year history of granulomatosis with polyangiitis consulted our hospital with a complaint of severe back pain. Computed tomography showed a large amount of gas located in his bowel wall and mesentery. He underwent urgent exploratory laparotomy, which led to a diagnosis of pneumatosis cystoides intestinalis without intestinal perforation or necrosis. He consequently underwent 13 sessions of hyperbaric oxygen therapy and was discharged from our hospital without complications.

Conclusions: Several previous reports have supported the efficacy of hyperbaric oxygen for treating pneumatosis cystoides intestinalis. The present case, however, is the first in which pneumatosis cystoides intestinalis in a patient with granulomatosis with polyangiitis was successfully treated with hyperbaric oxygen. We therefore suggest that hyperbaric oxygen therapy could be a candidate treatment for pneumatosis cystoides intestinalis in patients with granulomatosis with polyangiitis.
\end{abstract}

Keywords: Granulomatosis with polyangiitis, Pneumatosis cystoides intestinalis, Intestinal perforation, Hyperbaric oxygen therapy, Case report

\section{Background}

Granulomatosis with polyangiitis, also known as Wegener granulomatosis, is a small-vessel vasculitis that predominantly affects the upper and lower respiratory tract and the kidneys. Diarrhea, bleeding, and/or perforation have been reported as gastrointestinal complications

\footnotetext{
* Correspondence: tkato@jichi.ac.jp

'Department of Surgery, Yokosuka General Hospital Uwamachi, 2-36 Uwamachi, Yokosuka, Kanagawa 238-8567, Japan

${ }^{2}$ Department of Surgery, Saitama Medical Center, Jichi Medical University, 1-847 Amanuma-cho, Omiya-ku, Saitama 330-8503, Japan
}

of granulomatosis with polyangiitis [1]. Although gastrointestinal involvement in patients with granulomatosis with polyangiitis is rather uncommon, it is sometimes associated with mild to severe life-threatening complications [2]. Pneumatosis cystoides intestinalis is defined as the presence of gas within the gastrointestinal tract wall. When acute complications appear (for example, perforation, peritonitis, necrotic bowel), surgery is indicated [3]. We present a case of pneumatosis cystoides intestinalis in a patient already diagnosed with, and treated for, granulomatosis with polyangiitis. $\mathrm{He}$ was treated 


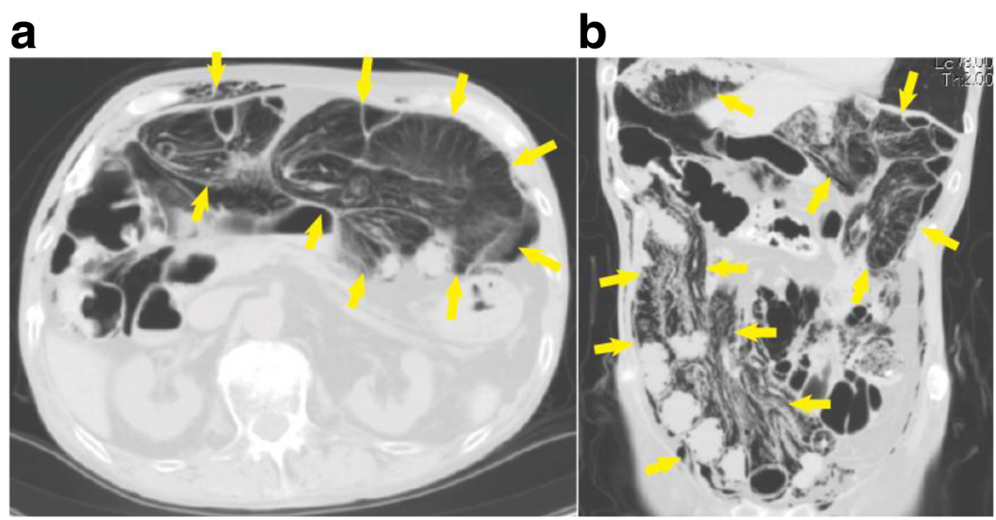

Fig. 1 Computed tomography shows a large amount of gas in the abdominal wall, bowel wall, and mesentery (arrows in axial view (a) and in coronal view (b)). It was difficult, however, to rule out the existence of free air in the abdominal cavity. Portomesenteric pneumatosis was not detected

successfully with hyperbaric oxygen ( $\mathrm{HBO})$ therapy for the pneumatosis cystoides intestinalis.

\section{Case presentation}

A 70-year-old Japanese man had a 3-year history of granulomatosis with polyangiitis that had manifested as multiple nasal nodules, pulmonary cavities, and serum antineutrophil cytoplasmic antibody-positive, necrotizing, crescentic glomerulonephritis. He had taken $15 \mathrm{mg}$ prednisolone and $150 \mathrm{mg}$ of mizoribine per day since the diagnosis. Cyclophosphamide or rituximab was not used. Three years after the diagnosis (at which point the total amount of prednisolone was $17.5 \mathrm{~g}$ ), he complained of severe back pain and consulted our hospital (Yokosuka General Hospital Uwamachi).

A physical examination revealed that his blood pressure was 143/93 mmHg, pulse rate 93 beats/minute, respiratory rate $16 /$ minute, and body temperature $36.6{ }^{\circ} \mathrm{C}$. His bowel sounds indicated hypoactivity, and his abdomen was distended but without tenderness. Laboratory analysis showed a C-reactive protein level of $12 \mathrm{mg} / \mathrm{dl}$ (normal 0 to $0.3 \mathrm{mg} / \mathrm{dl}$ ) and white blood cell count of $9700 / \mu l$. Blood gas analysis showed $\mathrm{pH} 7.378$, base excess $-6.0 \mathrm{mmol} / \mathrm{L}$, and lactate $1.1 \mathrm{mmol} / \mathrm{L}$. Computed tomography $(\mathrm{CT})$ showed a large amount of gas located in his abdominal wall, bowel wall, and mesentery (Fig. 1). It was difficult, however, to rule out the possibility of intestinal perforation or necrosis.

He underwent an urgent exploratory laparotomy, which led to a diagnosis of pneumatosis cystoides intestinalis without intestinal perforation or necrosis (Fig. 2). Two years before this diagnosis, multiple ulcers had been detected in his colon on the right side (Fig. 3), so we surmised that some of these ulcers had developed pneumatosis cystoides intestinalis. The day after the exploratory laparotomy, he started HBO therapy at 2.0 atmospheres absolute (ATA) for 90 minutes/day. The treatment duration was 17 days, with 13 sessions. Following $\mathrm{HBO}$ therapy, we found no evidence of pneumatosis cystoides intestinalis on CT scans (Fig. 4). He

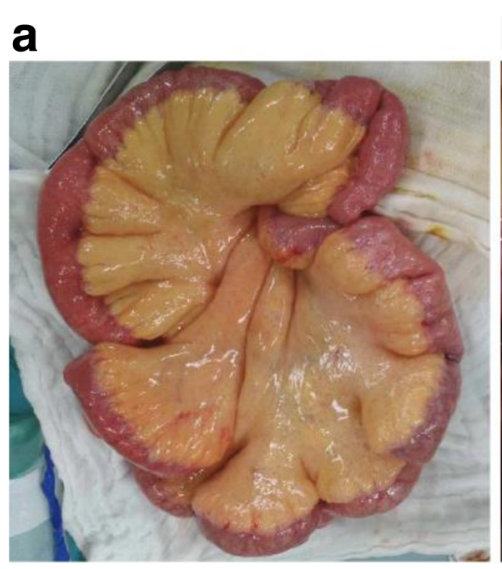

b

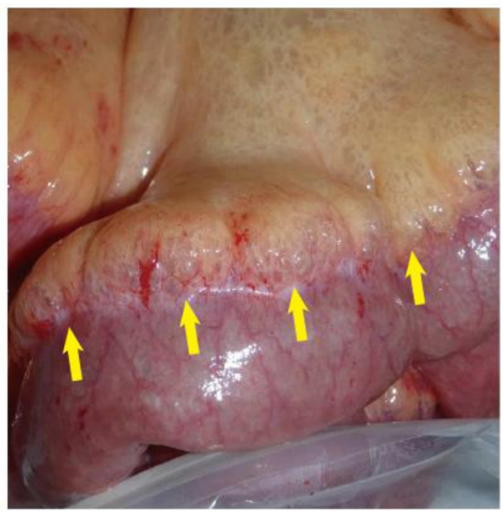

Fig. 2 Intraoperative exploratory laparotomy findings (Overall view (a)) revealed pneumatosis intestinalis without intestinal perforation or necrosis (arrows in (b)) 


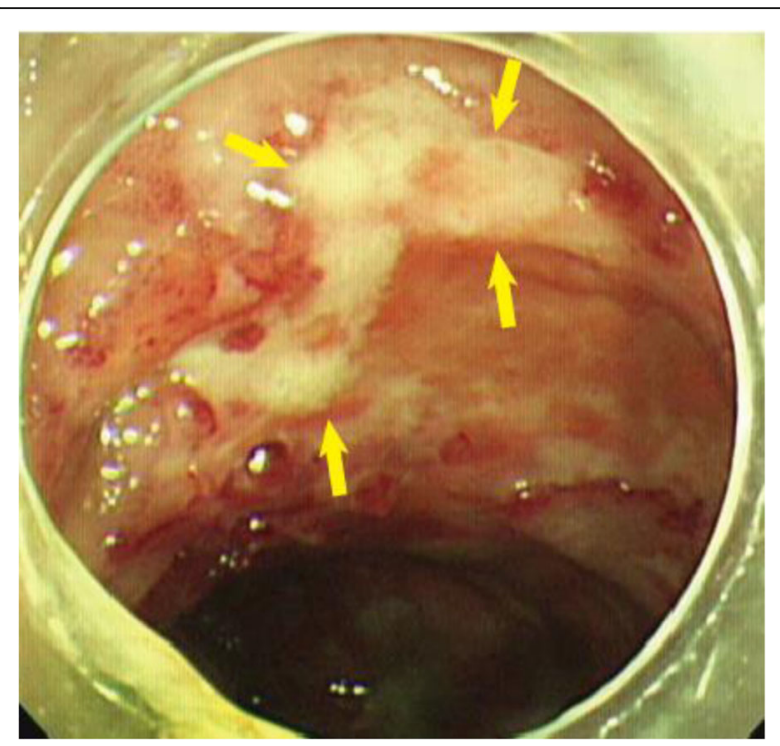

Fig. 3 The colonoscopy which was performed 2 years before the diagnosis of pneumatosis cystoides intestinalis showed multiple ulcers in his colon on the right side (arrows)

was discharged from our hospital without complications 19 days after completion of the HBO treatment. At his most recent follow-up, 3 years after being diagnosed with pneumatosis cystoides intestinalis, he was clear of the disease.

\section{Discussion}

We report the case of a patient with granulomatosis with polyangiitis who later developed pneumatosis cystoides intestinalis and underwent successful HBO treatment. To the best of our knowledge, this is the first case of pneumatosis cystoides intestinalis secondary to granulomatosis

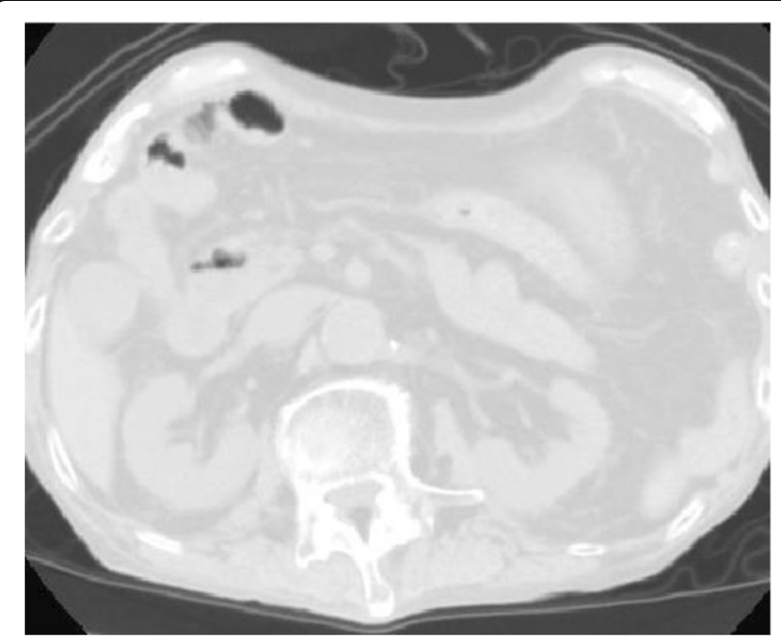

Fig. 4 Computed tomography after hyperbaric oxygen treatment shows no gas located in the abdominal wall, bowel wall, or mesentery with polyangiitis that has been successfully treated with HBO.

Pneumatosis cystoides intestinalis is an uncommon disease with an unknown etiology. It is characterized by the presence of gas within the submucosa or subserosa of the intestine [3-5]. Gastrointestinal involvement is not common in patients with granulomatosis, although there have been some reports of multiple ulcerations and intestinal perforation in patients with granulomatosis with polyangiitis [6-10]. Gagliardi et al. found mucosal and histologic abnormalities in patients with granulomatosis with polyangiitis [11]. Pneumatosis cystoides intestinalis has also been interpreted as evidence of intestinal ischemia and impending perforation [12].

$\mathrm{HBO}$ has long been recognized as an effective therapy for pneumatosis cystoides intestinalis, leading to cyst regression (determined by imaging) and symptom resolution [13]. A number of case reports have been published supporting the efficacy of $\mathrm{HBO}$ for treating pneumatosis cystoides intestinalis [14]. Standard HBO treatment is 2 to 3 ATA for 6 to 90 minutes/day for a duration ranging from 3 to 33 days [14]. In the present case, $\mathrm{HBO}$ effectively cured pneumatosis cystoides intestinalis in a patient with granulomatosis with polyangiitis, without complications.

\section{Conclusion}

We present a case of pneumatosis cystoides intestinalis in a patient with granulomatosis with polyangiitis that was treated successfully with $\mathrm{HBO}$.

\section{Abbreviations \\ ATA: Atmospheres absolute; CT: Computed tomography; HBO: Hyperbaric oxygen}

\section{Acknowledgements}

Not applicable.

\section{Funding}

No funding was received for this study.

\section{Availability of data and materials}

The authors agree to make the raw data and materials described in our manuscript freely available.

\section{Authors' contributions}

$\mathrm{KNa}$ and TK were the major contributors in writing the manuscript. SO, RM $\mathrm{KNi}, \mathrm{HK}$, and TS supervised the whole work. All authors read and approved the final manuscript.

\section{Ethics approval and consent to participate}

Not applicable.

\section{Consent for publication}

Written informed consent was obtained from the patient for publication of this case report and any accompanying images. A copy of the written consent is available for review by the Editor-in-Chief of this journal.

\section{Competing interests}

The authors declare that they have no competing interests. 


\section{Publisher's Note}

Springer Nature remains neutral with regard to jurisdictional claims in published maps and institutional affiliations.

Received: 25 November 2016 Accepted: 9 August 2017

Published online: 17 September 2017

\section{References}

1. Masiak A, Zdrojewski L, Zdrojewski Z, Bullo-Piontecka B, Rutkowski B. Gastrointestinal tract involvement in granulomatosis with polyangiitis. Prz Gastroenterol. 2016;11:270-5.

2. Fauci AS, Haynes BF, Katz P, Wolff SM. Wegener's granulomatosis: prospective clinical and therapeutic experience with 85 patients for 21 years. Ann Intern Med. 1983;98:76-85.

3. St Peter SD, Abbas MA, Kelly KA. The spectrum of pneumatosis intestinalis. Arch Surg. 2003;138:68-75.

4. Ivanovic A, Kovac J, Masulovic D, Stefanovic A, Jaksic E, Saranovic D. Education and imaging. Gastrointestinal: the role of multidetector computer tomography in diagnosis of pneumatosis cystoides intestinalis. Gastroenterol Hepatol. 2012;27:182

5. Wu LL, Yang YS, Dou Y, Liu QS. A systematic analysis of pneumatosis cystoids intestinalis. World J Gastroenterol. 2013;19:4973-8.

6. Geraghty J, Mackay IR, Smith DC. Intestinal perforation in Wegener's granulomatosis. Gut. 1986;27:450-1.

7. Tokuda M, Kurata N, Daikuhara H, Akisawa M, Onishi I, Asano T, Kobayashi S, Ohmori M, Irino S. Small intestinal perforation in Wegener's granulomatosis. J Rheumatol. 1989;16:547-9.

8. Skaife $\mathrm{P}$, Lee $\mathrm{S}$, Ramadwar M, Maitra D, Edwardson KF. Intestinal perforation as a presentation of Wegener's granulomatosis. Hosp Med. 2000;61:286-7.

9. Deniz K, Ozseker HS, Balas S, Akpynar E, Sokmensuer C. Intestinal involvement in Wegener's granulomatosis. J Gastrointestin Liver Dis. 2007;16:329-31.

10. Samim M, Pronk A, Verheijen PM. Intestinal perforation as an early complication in Wegener's granulomatosis. World J Gastrointest Surg. 2010;2:169-71.

11. Gagliardi G, Thompson IW, Hershman MJ, Forbes A, Hawley PR, Talbot IC. Pneumatosis coli: a proposed pathogenesis based on study of 25 cases and review of the literature. Int J Colorectal Dis. 1996;11:111-8.

12. Ngu J, Lieske B, Chan KH, Lim TZ, Cheong WK, Tan KK. Caecal pneumatosis is not an absolute contraindication for endoluminal stenting in patients with acute malignant large bowel obstruction. ANZ J Surg. 2014:84:772-5.

13. Forgacs $P$, Wright $P H$, Wyatt AP. Treatment of intestinal gas cysts by oxygen breathing. Lancet. 1973;1:579-82.

14. Feuerstein JD, White $N$, Berzin TM. Pneumatosis intestinalis with a focus on hyperbaric oxygen therapy. Mayo Clin Proc. 2014;89:697-703.

\section{Submit your next manuscript to BioMed Central and we will help you at every step:}

- We accept pre-submission inquiries

- Our selector tool helps you to find the most relevant journal

- We provide round the clock customer support

- Convenient online submission

- Thorough peer review

- Inclusion in PubMed and all major indexing services

- Maximum visibility for your research

Submit your manuscript at www.biomedcentral.com/submit 